\title{
Practice Note: Why We Started Talking About Menstruation-Looking Back (and Looking Forward) with the UN Special Rapporteur on the Human Rights to Water and Sanitation
}

\author{
Virginia Roaf and Catarina de Albuquerque
}

Virginia Roaf: Catarina, we have been asked to reflect on your work as Special Rapporteur on the human rights to water and sanitation, ${ }^{1}$ and how it was that we started to work on menstruation as a human rights issue over a decade ago. What do you remember of that time?

Catarina de Albuquerque: It is a great opportunity to look back and see how far we have come! It is already over a decade since I became Special Rapporteur-and so much has moved on since then in terms of discussions on menstruation and menstrual health and the importance of this for achieving gender equality. I started my mandate on human rights, water, and sanitation with a consultation on sanitation, as this was the aspect that needed the most attention. At that time, the right to sanitation was very much the poor cousin of the right to water. Further, 2008 was the first UN International Year of Sanitation, and as such, sanitation was being recognized as a 'problem child' of the Millennium Development Goals, always relegated to second place in comparison to water.

Virginia Roaf, specialist in the human rights to water and sanitation, was an advisor to Catarina de Albuquerque from 2010 to 2014.

Catarina de Albuquerque was the UN Special Rapporteur on the human rights to water and sanitation from 2008 to 2014 . 
Virginia Roaf: I remember that your focus on sanitation, both in your first report to the Human Rights Council on sanitation in 2009, as well as during your country visits to Costa Rica, Egypt, and Bangladesh of that year started you thinking about the need for better access to sanitation in schools, in particular for girls.

Catarina de Albuquerque: During those visits, I was particularly looking at girls' sanitation needs and, in visiting schools in Bangladesh, I learnt that girls' needs for privacy, adequate sanitation, clean water, and somewhere to change and wash themselves and menstrual products was preventing some adolescent girls from attending school. I also visited several community initiatives to raise awareness about menstrual hygiene, especially among adolescent girls. Menstruation was in Bangladesh, as elsewhere, taboo, and so I was impressed by the efforts of the communities I visited to ensure that girls are aware of adequate menstrual hygiene and that they have access to appropriate facilities. In my report to the Human Rights Council, I recommended that the government should ensure that women and girls have access to information about menstrual hygiene, and that sanitation facilities enable them to practice good menstrual hygiene (de Albuquerque 2009, Paras. 18, 69, 125).

Virginia Roaf: I remember that this was a pretty fertile time for those of us working with you on your mandate-we started working on menstruation at a broader level in response to what we learnt from women and girls following your country visits.

Catarina de Albuquerque: Absolutely, my visit to Bangladesh informed the rest of my mandate in terms of the needs of menstruating girls and women, not just in schools but across all aspects of their lives, at home, in the workplace and beyond. Menstrual hygiene and health became an additional consideration to be included within the requirements of the human right to sanitation, and all subsequent visits and most thematic reports included a consideration of the needs of women and girls due to their menstrual cycle as a matter of course.

Virginia Roaf: As I remember, one of the messages you wanted to convey over the course of your mandate was that human rights are universal and are to be applied equally all around the globe. People working within the development discourse often imagine that human rights are more likely to be violated in developing countries. What did you find with respect to menstruation in this regard?

Catarina de Albuquerque: While many may consider the taboos and stigma of menstruation to be something to be concerned about in developing countries, I found the same stories of discrimination when I visited Slovenia in 2010, when visiting a Roma community. One Roma woman told me about 
the shame she felt about the conditions in which she had to practice her menstrual hygiene. Even when the women were able to wash in the river in the spring and summer months, they risked being chased away by the local police, which they considered humiliating. This lack of adequate hygiene perpetuated discriminatory stereotypes about Roma among Slovenians, and I was keen to shine a light on that (de Albuquerque 2010, Para. 36).

The toll of poor menstrual hygiene and the stigma associated with menstruation on women and girls was also apparent in my mission to the Pacific Islands of Tuvalu adolescent girls told me that they sometimes skipped school during their periods because they could not afford to buy menstrual pads, and that families sometimes had to compromise on other daily necessities in order to provide their daughters with menstrual pads (de Albuquerque 2013b, Para. 32). Moreover, on the Pacific Islands (and I also visited Kiribati), disposal of all waste, including menstrual pads is a problem in atoll islands; Kiribati has no land on which to dump waste and does not recycle its waste (de Albuquerque 2013c, Paras. 35-36).

Virginia Roaf: What other experiences do you remember that women have shared about how they managed their menstruation?

Catarina de Albuquerque: On mission in Thailand, I remember asking one migrant worker how she bathed at the open bathing point especially during menstruation, and she told me: "I just shut my eyes and wash myself as quickly as possible, so that it is done" (de Albuquerque 2013a, Para. 25).

But the lack of attention to menstruation is something I recall everywhere I went. When I visited refugee camps in Jordan in 2014, one girl told me that the menstrual pads are such poor quality that she could not leave home for fear of leakage. I believe that this issue has since been addressed, and the menstrual pads provided by the humanitarian services have improved (de Albuquerque 2014a, Para. 53; see also Tellier et al. [Chapter 45] in this volume).

But the problem is the same whether among people in so-called developed or developing nations, refugees or nationals. On my visit to Kenya, women and girls shared their stories of how difficult it is to reconcile their menstruation days with attending school or working. A small pack of menstrual pads in Kenya costs KSh.80 on average; women in informal settlements and girls in communities living in poverty all said they could not afford them and therefore use a piece of cloth instead that can be difficult to wash out due to scarcity of water.

I was impressed by the courage of one girl in a remote area in Kanyadhiang who openly said, after being asked what she wanted most to have a better life "I want one more pair of panties because I only have one and I need to wash them daily and I want sanitary napkins" (de Albuquerque 2014b).

Virginia Roaf: Would you say that you had moments of hope, where women's and girls' needs were being considered? 
Catarina de Albuquerque: Absolutely, yes. In Turkana, the poorest county in Kenya, I learnt that the county government was providing menstrual pads to secondary school girls. This has since been expanded to cover all 4.2 million school girls in Kenya. I would love to see all countries in the world adopt similar measures, to give menstrual hygiene greater political and budgetary visibility for menstrual hygiene (de Albuquerque 2014a, Paras. 61, 80-81).

Virginia Roaf: I visited Kenya in late 2018, and the people you traveled with then are still talking of your visit and the recommendations that you made. Impressively, they have been incorporated into the work of the Human Rights Commission in Kenya, which now has a unit dedicated to the human rights to water and sanitation, and on an even better note, a menstrual hygiene policy is going through the final stages of approval in Kenya, and as you mentioned, free menstrual pads are now available in schools (Global Citizen 2018). Things do indeed change for the better (see Patkar [Chapter 38] in this volume)!

Catarina de Albuquerque: Meeting with girls and women and talking about menstruation on country visits was always a highlight. The discussions we had elicited much laughter, but also embarrassment. The stories that girls were telling about their experience of getting their first period, the lack of information on how their bodies were developing, what this meant for their lives, their worries about attending school, their lack of medical or social support with their periods rang true with me, and I think with all of us in the team. Perhaps because we were mostly (sometimes exclusively) female, we could relate to what women and girls were experiencing.

Virginia Roaf: I think that in our sector, we often focus on the material solutions, better construction, the technologies, even better menstrual products. But within these stories, it became clear that the problem also contained an enormous need for education, understanding, and for acceptance-not just for girls, but for boys, for women and men, for the whole of society to be better informed on menstruation.

Catarina de Albuquerque: Absolutely, it was through these discussions with girls and women on country visits, that I identified the stigmatization of women due to their periods as a significant barrier to resolving a whole host of other issues related to menstruation, such as reproductive health, education, and gender equality. And since the unique mandate of a Special Rapporteur is listening, I was able to experience the lived experiences of women and girls and then take these to the level of the UN in an attempt to influence policy-making and programming.

Virginia Roaf: I remember that one of the most significant issues was a lack of data - and the information that existed was full of assumptions and anecdotal evidence. Considering women and girls' needs relating to 
menstruation, and their negative experiences relating to menstruation, all over the world, certainly not limited to developing countries, we identified the need for more research, as data on women and girls' menstrual needs was, and continues to be extremely limited. We also identified taboos suggesting that people consider menstrual blood to be 'dirtier' than other blood. Specifically, I remember working with you to prepare your keynote at a session at the World Water Forum in Marseille, in 2012, and that was one of the first times that menstruation had a dedicated session. What do you remember of that event?

Catarina de Albuquerque: I was invited by the UN Water Supply and Sanitation Collaborative Council to give the keynote at their session on menstruation, in recognition of the work that I had already done to popularize menstrual hygiene as a significant barrier to the realization of the human rights to water and sanitation. In my address, I identified the taboo of menstruation preventing progress on the achievement of gender equality. In fact, I remember starting that keynote stating that I, too, menstruate, and it was seen as a brave intervention!

Virginia Roaf: I believe it was partly in response to these discussions that we decided to dedicate your 2012 report to the Human Rights Council to the impact of stigma on the realization of the human rights to water and sanitation.

Catarina de Albuquerque: Yes, it was clear to me that we needed to look at discrimination in a more nuanced way, and we decided to focus on stigma as one of the key underlying factors that influences so many of our perceptions of women and girls. Of course, menstruation had to be part of that. At the time, I wrote:

The silence and stigma surrounding menstruation makes finding solutions for menstrual hygiene management a low priority. Menstruating women and girls often lack a private place to change or wash the rags used. Menstruation has many negative cultural attitudes associated with it, including the idea that menstruating women and girls are contaminated, dirty, impure or polluted. These manifest in practices such as the seclusion of women and girls, reduced mobility, dietary restrictions, and/or women and girls being required to use different water sources or prohibited from preparing food for others during menstruation practices that are often deeply rooted in sociocultural and patriarchal interpretations of religious prescriptions. Even where such restrictions are not followed, women and girls may continue to harbour internalized stigma and are embarrassed to discuss menstruation. The lack of privacy for cleaning and washing, the fear of staining and smelling, and the lack of hygiene in school toilets are major reasons for being absent from school during menstruation, and have an education. (de Albuquerque 2012, Para. 25) 
Virginia Roaf: As I remember, it was about this time that we started engaging with discussions on the post-2015 agenda (which became the Sustainable Development Goals or SDGs). Our goal was to integrate attention to menstrual hygiene at yet another level. Your team was represented in all the water, sanitation, and hygiene preparatory technical working groups, including the sanitation and hygiene working groups in particular. At the end of the process, in November 2012, we recommended that menstrual hygiene to be included in the future post-2015 goals, targets, and indicators (UNICEF/ WHO Joint Monitoring Programme 2013, 2-3, 6). While this recommendation was not included in the Sustainable Developments Goals themselves, different UN agencies, including the UNICEF/WHO Joint Monitoring Programme, have emîbarked on significant efforts to improve monitoring of menstrual hygiene and to collect more comprehensive data on menstruation (see Loughnan et al. [Chapter 44] in this volume).

Virginia Roaf: It is now nearly ten years later and it is interesting to reflect how far the conversation has come. A film on menstruation has even won an Oscar this year-what should we take from this?

Catarina de Albuquerque: It's true, and gratifying that this issue has been taken up so widely and with such enthusiasm across the globe. Menstrual hygiene and health have become part of mainstream policy-making, programming, and advocacy efforts. Organizations and governments are working on a range of aspects related to menstrual health including sexual and reproductive rights. There is a marked difference to when we started talking about menstruation. The menstrual health agenda is starting to reach far beyond the Water, Sanitation and Hygiene (WASH) sector which is essential to address the full range of human rights issues related to menstruation.

Virginia Roaf: Yes. And yet, over a decade ago, the WASH sector was an ideal entry point for starting the conversation on menstrual health. What prompted us to consider menstruation as part of your mandate on water and sanitation were the stories women and girls told you. They mentioned their very real needs in terms of access to facilities and materials. The predominantly male engineers working in water and sanitation were surprised to hear that menstrual hygiene was something that also lay within their remit, but once the initial surprise was overcome and the silence around menstruation was broken, most WASH sector professionals were open and eager to address the issue and to start finding solutions for the immediate needs by women and girls. This focus on tangible and concrete measures is a huge part of what triggered the increasing efforts on menstrual hygiene management.

Frustrating as it remains that many women have the primary role as homemakers and as caregivers, water and sanitation are still particularly critical issues for women. Therefore, I do feel that considering menstrual health through the lens of the human rights to water and sanitation still 
makes sense, although I think it is not the only lens that we should be using. Through access to adequate water and sanitation services, which include consideration of privacy and dignity, and which comply with the standards of the human rights to water and sanitation, many issues relating to menstrual hygiene and health will be addressed. Adequate water for washing ourselves and our menstrual pads, a place to safely dispose of used menstrual materials, sanitation facilities available at school, at the workplace, and elsewhere, these services address requirements for menstrual hygiene. And precisely because the WASH sector is perceived as rather technical, it provided an 'innocuous cover' to start addressing issues that are ultimately about deeply entrenched gender norms.

Catarina de Albuquerque: I absolutely agree. But at the same time these benefits point to the risks associated with addressing menstruation exclusively through the lens of WASH due to the heavy focus on tangible outputs, facilities, and the provision of materials. While the WASH sector proved to be an excellent entry point, we must get past this narrow understanding of menstrual hygiene to fully embrace menstrual health. The World Health Organization defines health as "a state of complete physical, mental and social well-being and not merely the absence of disease or infirmity" (WHO 1946) and we must embrace all these dimensions in relation to menstruation. This entails education, reproductive and mental health, working conditions, as well as sociocultural taboos. To manage our periods and menstrual health more generally, it is essential that we understand how our bodies work and are able to fluently express what we need in terms of help or support when things go wrong. The taboos regarding menstruation, for example, extend to the lack of attention that the medical profession pays to poor menstrual health. For example, the symptoms of endometriosis are not well understood and too often dismissed by health care providers. Women and girls need better education about their bodies. Men and boys must also be educated on the menstrual cycle and women and girls' needs to manage their menstruation, so that they can respond with understanding and not fear. Menstruation is also deeply enmeshed with cultural and religious traditions, and we need to approach the discussion of such practices with more nuance. I am emboldened by the efforts of women and girls across the globe to treat menstruation as a fact of life and to resist attempts to restrict them, for instance from accessing cultural or religious sites.

Reflecting on where we began over a decade ago and how far we have come, I think we are truly beginning to realize that menstruation is a gender equality issue that affects the realization of all human rights. Menstruation is about so much more than blood and the materials and services (in the context of WASH) that we need to deal with it. I am glad that we were able to identify this entry point in the WASH sector and that I could contribute to normalizing menstruation all over the world, beginning with my discussions with the girls in Bangladesh to the Palais de Nations in Geneva. 


\section{Note}

1. An independent expert mandated by the UN to promote compliance with and examine violations of the human rights to water and sanitation.

\section{REFERENCES}

de Albuquerque, Catarina. 2009. "Report from the UN Independent Expert on the Issue of Human Rights Obligations Related to Access to Safe Drinking Water and Sanitation on Her 2009 Mission to Bangladesh." Human Rights Council, A/ $\mathrm{HRC} / 15 / 55$.

de Albuquerque, Catarina. 2010. "Report of the Special Rapporteur on the Human Right to Safe Drinking Water and Sanitation on Her 2010 Mission to Slovenia." Human Rights Council, A/HRC/18/33/Add.2.

de Albuquerque, Catarina. 2012. "Report of the UN Special Rapporteur on the Human Rights to Water and Sanitation on Stigma and the Realization of the Human Rights to Wand Sanitation." Human Rights Council, A/HRC/21/42.

de Albuquerque, Catarina. 2013a. "Report of the Special Rapporteur on the Human Right to Safe Drinking Water and Sanitation on Her Mission to Thailand." Human Rights Council, A/HRC/24/44/Add.3.

de Albuquerque, Catarina. 2013b. "Report of the Special Rapporteur on the Human Right to Safe Drinking Water and Sanitation on Her Mission to Tuvalu." Human Rights Council, A/HRC/24/44/Add.2.

de Albuquerque, Catarina. 2013c. "Report of the Special Rapporteur on the Human Right to Safe Drinking Water and Sanitation on Her Mission to Kiribati." Human Rights Council, A/HRC/24/44/Add.1.

de Albuquerque, Catarina. 2014a. "Report of the Special Rapporteur on the Human Right to Safe Drinking Water and Sanitation on Her Mission to Jordan." Human Rights Council, A/HRC/27/55/Add.2.

de Albuquerque, Catarina. 2014b. "Statement by the United Nations Special Rapporteur on the Human Right to Water and Sanitation on Her Visit to Kenya." July 22-28. Accessed April 20, 2019. https://www.ohchr.org/EN/NewsEvents/ Pages/DisplayNews.aspx?NewsID $=14912$ \&LangID $=E$.

Global Citizen. 2018. "4 Million Kenyan Schoolgirls Are Going to Receive Free Sanitary Pads.” Accessed at: https://www.globalcitizen.org/en/content/ kenya-schoolgirls-free-pads/.

UNICEF/WHO Joint Monitoring Programme. 2013. "Proposal for Consolidated Drinking Water, Sanitation and Hygiene Targets, Indicators and Definitions.” World Health Organization. 1946. "Constitution." 
Open Access This chapter is licensed under the terms of the Creative Commons Attribution 4.0 International License (http://creativecommons.org/licenses/ by $/ 4.0 /)$, which permits use, sharing, adaptation, distribution and reproduction in any medium or format, as long as you give appropriate credit to the original author(s) and the source, provide a link to the Creative Commons license and indicate if changes were made.

The images or other third party material in this chapter are included in the chapter's Creative Commons license, unless indicated otherwise in a credit line to the material. If material is not included in the chapter's Creative Commons license and your intended use is not permitted by statutory regulation or exceeds the permitted use, you will need to obtain permission directly from the copyright holder. 